Behav Processes. 1998 December ; 44(2): 211-224. doi:10.1016/S0376-6357(98)00050-3.

\title{
Watching the clock
}

\author{
J. Gregor Fetterman ${ }^{a}$, Peter R. Killeen ${ }^{b},{ }^{*}$, and Scott Hall ${ }^{b}$ \\ a Indiana University, Purdue University, Indianapolis IN, USA \\ ${ }^{b}$ Arizona State University, Tempe AZ85287-1104, USA
}

\begin{abstract}
Four rats and four pigeons were monitored while performing retrospective timing tasks. All animals displayed collateral behaviors which could have mediated their temporal judgements. Statistical analysis made a good case for such mediation in the case of two pigeons performing on a spatiallydifferentiated response, but not for the two responding on a color-differentiated response. For the rats, all of which performed on a spatially-differentiated task, prediction of their temporal judgements was always better if based on collateral activity than if based on the passage of time.
\end{abstract}

\section{Keywords}

Behavioral mediation; Causal analysis; Collateral behavior; Correlational analysis; Pigeons; Rats; Time

\section{Introduction}

When asked to time an interval, humans almost invariably count. They count 'thousands', or 'hippopotamuses' or 'Mississippis' or foot-taps. This is true both for adults and for children over 6 years (Wilkening et al., 1987). A minority of humans use visual imagery, such as watching the hands on an imagined clock (Feynman and Leighton, 1988). Most theories of timing assume just such count-mediated timing, and their resulting models are germane to human temporal judgements (Wearden, 1991). They have less face validity for non-verbal organisms. How do pigeons and turtles (Lejeune and Wearden, 1991) use a counter if they can't count?

\begin{abstract}
Some non-human animals can count (Davis and Pérusse, 1988), but not very high, not very well, and they'd really rather not at all (Breukelaar and Dalrymple-Alford, 1998). Meck (1997) provides a thoughtful analysis of the appropriate criteria for attributing numerical competency to animals in the light of their impressive — but inherently analog-performance in counting tasks. It remains a challenge to theories of timing to explain what it means for animals that can't count to count seconds. One response to the challenge is the seminal Scalar Expectancy Theory of Gibbon and Church (Church et al., 1992; Gibbon and Church, 1992), which posits such counting as an intrinsic property of the counter. Another is the connectionist model of Broadbent and Church (Church and Broadbent, 1990, 1991), which avoids counting by positing vector multiplication of banks of registers that are driven by a bank of synchronized pacemakers.
\end{abstract}

Another response is the 'behavioral' theory of timing (BeT, Killeen and Fetterman, 1988; Machado, 1997) predicated on two assumptions: (a) temporal discriminations and productions

\footnotetext{
* Corresponding author. Tel.: + 1602 9652555; fax: + 1602 9658544; e-mail: killeen@asu.edu.
} 
are mediated by a pacemaker-counter system in which collateral behaviors function as the counter, enabling an organism to identify its location in time through its discriminations of ongoing activities; and (b) transitions between classes of collateral activities are produced by pulses from a pacemaker whose period is proportional to the average interval between reinforcers. If true, this model would support only the lowest, nominal, form of timing: some collaterals are cues for one temporal judgement, other collaterals cues for other judgements, but the animals are neither required nor expected to have any sense of 'beforeness' or 'betweeness' or 'afterness'. Timing ability depends on there being a natural progression through chains of collateral responses, but if those should occur out of order, so too would temporal judgements. Whereas animals may know what to do next in a chain of responses, that is not the same as mapping them in toto onto an ordinal or interval continuum. Carr and Wilkie (1997) provide an excellent review of the evidence for various levels of timing in different species.

The variable-speed pacemaker assumption has been tested in experiments from our laboratories (Morgan et al., 1993; Fetterman and Killeen, 1995), and from others (Bizo and White, 1994). The results support the general assumption that pacemaker rate varies with arousal (Wearden and Pentonvoak, 1995; Killeen et al., 1998), but not the specific assertion of strict proportionality between clock-speed and reinforcement rate (Beam et al., 1998).

By contrast, the question of behavioral mediation of temporal discriminations has not been so systematically addressed, at least in the context of BeT. Although such mediation is the only truly behavioral aspect of $\mathrm{BeT}$, and therefore the one most amenable to visual inspection, it has been taken as something of an article of faith until now. Casual observations of birds oscillating in front of one key then the other, or of rats moving from one location and to another in a repetitive fashion, provided provisional reassurance (Fetterman and Killeen, 1991), generalization from the behavior of larger animals (Bem, 1970) provided additional circumstantial evidence. Animals will often mediate delayed temporal discriminations with collateral behavior (Shimp and Moffitt, 1977; Chatlosh and Wasserman, 1987). But is that the basis for non-delayed discriminations?

The literature proves ambivalent. Richelle and Lejeune (1980) addressed the question of behavioral mediation of timing head-on. After a thorough review of the ways in which collateral behavior can facilitate timed performances, they summarized: 'Where consistent collateral behaviour is observed, temporal responding is more efficient.... When it is disrupted, the temporal characteristics of responding are also often disrupted.' (pp. 189-190). Nonetheless, they concluded that collateral behaviors are not substitutes for timing mechanisms (p. 196). The reasons included: (a) chaining of one collateral behavior from the preceding one (i.e. a sequence of necessary links) was not supported; (b) in many cases, collateral behaviors consist of the repetition of just one stereotyped activity; (c) collateral behaviors are not always observed; (d) training mediating behavior may not help timing; (e) sometimes they occur when they are not fulfilling a necessary timing role; (f) they are unreliable [also see Reid et al. (1993)]; (g) although severe restriction of movement completely undermines timing, something is learned by the subjects, because when unbound they catch up to control, unrestricted subjects in just a few sessions.

Consistent with this analysis, McIntire and associates (McIntire et al., 1983) built an apparatus with multiple compartments in which rats could emit various collateral behaviors. When they disrupted sequences of responses by blocking preferred chambers, they found little discernible increase in response rates on DRL schedules in most cases. They concluded that their results gave no support to the hypothesis that collateral behaviors had a timekeeping or discriminative function. 
These scholarly analyses and experiments constitute hurdles for the behavioral theory of timing. Some of the objections are not pertinent: taken in order (a) it is not necessary to assume that a sequence of interim (Staddon, 1977) behaviors constitutes a chain (Killeen and Fetterman, 1993); (b and c) the failure to observe collateral behaviors, or to see only one type, may reflect a lack of acuity: relatively subtle changes in topography of interim responses may suffice as distinct markers, being more salient to the rat than to the graduate student observing it; (d) by definition, something is always being strengthened by a reinforcer, whether or not the experimenter observes it; explicitly training collateral activities may interrupt the flow of naturally occurring ones; (e) it is not assumed that the purpose of collateral behaviors is to aid timing; rather they are elicited by the context and history of the organism, if they stand in a regular relation to accurate temporal behavior, they will naturally be conditioned as discriminative stimuli. Timing behavior exploits all relevant cues, which may acquire distinctiveness and become exaggerated by a successful role as discriminative stimuli, but they need not be created for that purpose; (f) collateral behaviors are irregular, in like manner, timing is imperfect. Other objections, such as the latent learning of temporal regularities by restricted animals, and the inability to disrupt timing by disrupting access to collateral behaviors, are beyond peremptory resolution.

The problem for those who would deny a timing role for collateral activity, no matter how correct they might be, is that of asserting the null. Those cited have been mindful of that difficulty and careful in couching their conclusions. Conversely, the problem for those, such as ourselves, who would assert such a role for collateral activity is the recognition that even if a causal role is demonstrated in one study or organism, it does not entail that such behavioral mediation is generally necessary for efficient timing: there may be other situations where it's all done in the head.

The next step is to move from hypothetical to empirical, and to provide some data that might move the discussion ahead. To this end, systematic observations were made of rats and pigeons trained to discriminate the duration of a signal. Subjects were videotaped as they discriminated between short and long signals, and the behaviors during the signal were related to subjects' subsequent classifications of signal duration.

No attempt was made in these studies to disrupt the animals' collateral behaviors to ascertain whether more timing errors might then occur. Such experiments have been conducted with positive results, as noted above. Here the effects of disruption-without the confound of a disruptor-are brought about by increasing the difficulty of the task. Experimental interventions (e.g. precluding a putative mediating behavior) are generally more powerful than correlational analyses at avoiding confounds, but carry with them their own burden of threats to validity. The present study provides an opportunity to press the correlational approach to its limits.

\section{Materials and methods}

\subsection{Subjects}

2.1.1. Rats-The subjects were four adult male albino rats (Sprague Dawley) about 200 days old. The rats had previously learned to lever-press in an undergraduate operant laboratory course, none of their undergraduate laboratory experiences involved timing tasks. The rats were maintained at about $80 \%$ of their free-feeding weights and received supplemental feedings, when necessary, to maintain their experimental weights. The animals were housed individually, with unlimited access to water. 
2.1.2. Pigeons-The subjects were four adult male Silver King pigeons maintained at $\approx 80 \%$ of their free-feeding weights. The pigeons received unlimited access to water and grit in their home cages. The birds were experimentally naive at the beginning of the experiment.

\subsection{Apparatus}

2.2.1. Rats-The experimental enclosure was a standard BRS-LVE rat chamber with two retractable levers. The enclosure measured $25 \mathrm{~cm}$ across the front and back walls and $30 \mathrm{~cm}$ along the side walls. The side and back walls were translucent plexiglas, the work panel (front wall) was stainless steel. The floor was a stainless steel grid. The left and right levers were 17 $\mathrm{cm}$ apart, center-to-center, and about $5 \mathrm{~cm}$ above the grid floor. The levers were $2.5 \mathrm{~cm}$ wide and $5 \mathrm{~cm}$ long. Three jewel lights were arrayed in a row about $1.5 \mathrm{~cm}$ above each lever. The food cup was centrally located between the levers, about $2 \mathrm{~cm}$ above the floor. The pellet dispenser was located behind the work panel. Experimental events were scheduled and recorded by an Apple IIe computer and MED associates interface located in an adjacent room.

2.2.2. Pigeons-The experimental enclosure was a BRS-LVE three-key pigeon chamber, whose work space measured $32 \mathrm{~cm}$ high $\times 34 \mathrm{~cm}$ wide $\times 34 \mathrm{~cm}$ deep. The keys were accessible through $2 \mathrm{~cm}$ circular openings in the front wall, the center of the openings were spaced 6.3 $\mathrm{cm}$ apart, $24 \mathrm{~cm}$ above the chamber floor. A force of $\approx 0.15 \mathrm{~N}$ was required to operate the keys. The houselight was located above the center key, about $31 \mathrm{~cm}$ above the floor $(4.5 \mathrm{~cm}$ above the top of the center key). The houselight was a standard $28 \mathrm{~V}$ bulb covered by a metal shield opening upward. The feed opening was located directly below the center response key and measured $5 \mathrm{~cm}$ on all dimensions, the bottom of the feeder opening was $10 \mathrm{~cm}$ above the chamber floor. White noise served to mask extraneous sounds, additional masking and ventilation were provided by an exhaust van attached to the chamber wall. The hinged chamber door was replaced by a piece of translucent plexiglas and the video recorder was placed about $0.8 \mathrm{~m}$ directly opposite the plexiglas wall (located to the side of the panel containing the response keys). Experimental events were scheduled and recorded by an IBM PC and interface located in an adjacent room.

\subsection{Procedure}

2.3.1. Pigeons-After magazine training the pigeons were trained to key peck with an autoshaping procedure (Brown and Jenkins, 1968) under which they received 90 trials per session for five sessions. A trial commenced with the onset of an amber light behind one of the pecking keys, a peck to the lit key activated the hopper, providing $3 \mathrm{~s}$ access to mixed grain immediately. If no peck occurred with $5 \mathrm{~s}$ of light onset, the light was turned off and the food hopper was then activated for $3 \mathrm{~s}$. Food presentations were followed by an intertrial interval (ITI) that lasted for $30 \mathrm{~s}$. The keylights were presented in a quasi-random order across trials, and each key was lit 30 times in each session. This procedure produced reliable pecking on all keys by all birds within five sessions.

Once key pecking was established all pigeons were placed on a temporal discrimination task in which different choice responses were reinforced after different durations of the houselight. Trials began with the illumination of the houselight, which lasted $6 \mathrm{~s}$ ('short') on one half of the trials and $12 \mathrm{~s}$ ('long') on the remaining trials. At the end of the scheduled duration the houselight was turned off and the left and right keys were illuminated with red and green lights (the center key remained darkened and inoperative throughout the experiment). A response to one of these keys was correct after short signal durations and a response to the other was correct after long signal durations. Correct responses turned off the key lights and produced $3 \mathrm{~s}$ access to mixed grain followed by a $15 \mathrm{~s} \mathrm{ITI}$, incorrect responses simply turned off the key lights and initiated the ITI. All lights were off during the ITI. A correction procedure (erroneous trials were replayed) was used only during the first 15 sessions of training. Sessions were conducted 
6 days per week and ended after 80 trials. The video recorder was present throughout training, placed about $0.8 \mathrm{~m}$ directly opposite the plexiglas wall, taping was not commenced until the discrimination was learned and stable.

Two pigeons were trained under a spatial choice arrangement. One pigeon was trained to peck the left key after the shorter ( $6 \mathrm{~s})$ signal and the right key after the longer (12 s) signal. The correct key location assignments after short and long durations were reversed for the other bird.

The other two pigeons were trained under a nonspatial task in which the position of the key colors alternated randomly across trials, and correct responses were defined in terms of key color, not key location. One bird was trained to peck the red key after short durations and the green key after long durations, this arrangement was reversed for the other bird [see Chatlosh and Wasserman (1987), for comparisons of spatial and nonspatial temporal discrimination tasks]. The pigeons were trained for an average of 47 sessions (41-51), after which videotaping commenced for an additional 3-5 sessions. When the first round of videotaping was finished the discrimination was made more difficult by reducing the duration of the long stimulus from 12 to $9 \mathrm{~s}$. Training under the more difficult discrimination lasted for 20 sessions, followed by five sessions of videotaping.

2.3.2. Rats-The rats had previously learned to lever press for food reinforcement, and were placed directly on a procedure very similar to the one used with the pigeons. Trials began with the onset of a signal, which consisted of the concurrent illumination of the center jewel lamps above the lever locations and of the houselight. The signal lasted for 6 or $12 \mathrm{~s}$ and was followed by the insertion of the levers into the chamber. A response to one lever was correct after the short signal and a response to the alternate lever was correct after the long signal. The lever location (left vs. right) and signal duration (short vs. long) contingencies were counterbalanced across animals. A response to either lever caused the levers to be retracted. Correct responses produced a $45 \mathrm{mg}$ Noyes food pellet followed by a $30 \mathrm{~s} \mathrm{ITI}$, incorrect responses initiated the ITI directly. All lights were off during the ITI. During the first 15 sessions of training only a correction procedure was used (incorrect trials were replayed). Sessions were conducted 6 days per week and ended after 60 trials. The rats were trained for an average of 64 sessions (58-70) until performance stabilized and then 5 (Rats 4 and 6) or 6 sessions (Rats 1 and 5) were videotaped for observational analysis. The video camera was present throughout training.

\subsection{Recording program and inter-observer agreement}

Two observers viewed the video tapes and coded the ongoing behaviors in one- second bins during each trial. The raters were not told the motivating hypothesis. Only a single behavioral category was recorded for each time bin. The observers scored the same tapes for five animals ( 2 rats and 3 pigeons). Their ratings were compared for estimates of reliability. The raters jointly scored a single session for one of the pigeons trained on the spatial choice arrangement (Bird 62) and the reliability of their observations was estimated by calculating the percentage agreement of their observations, and kappas (Bakeman et al., 1997), the raters agreed on 85\% of their scores (475 of 558 comparisons), a respectable level of reliability.

The pigeons trained on the nonspatial choice discrimination did not engage in heterogeneous sequences of adjunctive behaviors (see below), but emitted homogenous sequences of the same activity (e.g. pecking at the signal light). As a consequence, the raters counted the number of occurrences of these activities on each trial. Estimates of reliability were obtained by correlating the raters' counts. The correlations were above 0.99 for both pigeons (Birds 54 and 12). The raters scored pairs of sessions for two of the rats.

The percentage agreement in their scoring was 78\% for Rat 4 (420 of 540 comparisons) and $84 \%$ for Rat 5 (452 of 535 comparisons). The medians and ranges of the values of kappa 
calculated for all responses that occurred more than $1 \%$ of the time were: Rat $4,0.70(0.61-$ 0.72); Rat 5, 0.81 (0.74-0.94); Bird 62, $0.75(0.60-0.86)$.

\section{Results}

\subsection{Rats}

Fig. 1 shows the distribution of various collateral behaviors through the interval. Note that half the trials ended at $6 \mathrm{~s}$, so that the symbols after $6 \mathrm{~s}$ reflect those data collected on long trials only. All rats showed an increasing rate of sniffing around the 'long' lever as time passed through the trial, and this exceeded 50\% in all rats after the tenth second of the trial. Sniffing the 'short' lever increased to a mode that, on the average, occurred at the sixth second. Rat 1 showed monotonic decreases in grooming and rearing through the interval, it's mouthing of the dispenser was correlated with sniffing of the short lever. Rat 4 showed a monotonic decrease in rearing and mouthing the dispenser through the trial. Rat 5 showed a distinctive peak in mouthing the dispenser at the sixth second.

The subjects had twice as many opportunities opportunities to emit a collateral behavior up through $6 \mathrm{~s}$ as they did thereafter, and the denominators were adjusted appropriately in calculating probabilities. For instance, for Rat 1 'sniffing long' occurred 12 times during the first second and 114 times during the twelfth second. Over the six sessions of observation, there were 360 observations at $1 \mathrm{~s}$ and 180 at $12 \mathrm{~s}$. Therefore the probability of 'sniff long' at these times was $0.03(12 / 360)$ and $0.63(114 / 180)$.

\subsection{Causal analysis}

Some of these behaviors show the temporal patterns that are necessary for them to be conditioned as cues to the appropriate response. Others do not change appreciably over time, and therefore would not suffice as cues. A finer analysis is possible if we ask what is the probability of an animal's making a particular judgmental response, $R_{\mathrm{S}}$, or $R_{\mathrm{L}}$, given that they have engaged in some collateral behavior, $C_{i}$, in the preceding second ${ }^{1}: p\left(R_{j} \mid C_{i}\right)$ ? This statistic is listed in Table 1 . As that conditional probability approaches 1 , we may say with increasing confidence that $C_{i}$ is sufficient for $R_{j}$. It only tells half the causal story, however; if the baserate of the collateral behavior is low, some of the choice responses may be based on other mediators. For instance Rat 5 may be guided by sniffing on some trials and by mouthing on other trials. We may infer how necessary a particular collateral behavior is by calculating the probability that it occurs just before a particular choice response: $p\left(C_{i} \mid R_{j}\right)$. This statistic is also listed in Table 1 . The extent to which a collateral behavior is both necessary and sufficient may be inferred by combining these two kinds of causal information. One way to do that is by using Yule's $Q$ statistic (Hall and Oliver, 1997). The appendix shows how this is calculated, and provides the null-test statistic (Bakeman and Quera, 1995). Only those collateral behaviors that showed $Z$-scores in excess of 3.0 are listed in Table 1.

If the $Q$ statistic for a collateral and pressing the 'long' lever is 0.993 , then the $Q$ value for its association with pressing the 'short' lever is -0.993 . Similarly for $Z$. Thus, a significant $Q$ or $Z$ tells us that there is a significant differential association.

\subsection{Pigeons}

Fig. 2 provides a similar picture of the collateral activities of pigeons on the spatially differentiated response task, for the easy (6-12, top row) and the more difficult (6-9, bottom row) discriminations. It is clear that after some initial behaviors, these animals began pecking

\footnotetext{
${ }^{1}$ Analysis of the preceding $2 \mathrm{~s}$ did not substantially improve predictive ability; interactions of sequences of prior behaviours were not considered out of parsimony.
} 
at (Bird 62) or in front of (Bird 91, 'bobbing') the 'short' key, which either found a mode around 5-6 s (62) or which decreased regularly through the interval (91). Similar activities at or in front of the 'long' key emerged toward the end of the trial. Not all pigeons engaged in all behaviors listed in the legend. For instance, Bird 91 never pecked in front of the 'long' key. A statistical analysis similar to that conducted for rats was employed in analysing these data, and those results are listed in Table 2, which shows that responses near the keys were excellent predictors of the subsequent choice response.

Two of the pigeons were trained on the same temporal discriminations using a colordifferentiated (non-spatial) response task. Both birds achieved accurate performances ( 87 and $95 \%$ on the easy discrimination, and 80 and $82 \%$ on the difficult discrimination for 12 and 54, respectively). Both developed collateral behavior of pecking at the houselight (Bird 54) or head-bobbing in the right front corner of the chamber (Bird 12), with few other noticible collateral behaviors. Fig. 3 shows the frequency distributions of the number of such pecks before a 'short' or 'long' response. Each data point represents the probability that the bird made a particular number of responses (e.g. pecking the houselight) before pecking the 'short' or 'long' key. The disks show the distributions on trials that ended with a 'short' response, and the circles show the distributions on trials that ended with a 'long' response. Bird 12, for instance, almost always made between 12 and 20 head bobs before the former, and 30-40 (easy discrimination) or 25-30 (difficult discrimination) before the latter. It is clear that these largely non-overlapping distributions could serve as the basis of the temporal discrimination, indeed they appear similar to the distributions of signal and noise used to illustrate the hypothetical mediators of signal detection tasks.

Further analysis is necessary before we can conclude that such collateral behavior actually mediated the discrimination. That is provided by analysis of the error distributions on short trials and on long trials. If such collateral pecking mediated the discrimination, then we would expect that on those $6 \mathrm{~s}$ trials when the pigeon incorrectly responded 'long', the number of collateral pecks would be larger than on those $6 \mathrm{~s}$ trials when it responded 'short'. The same analysis is possible for 9 and $12 \mathrm{~s}$ trials. Table 3 shows the results of this analysis. In no case did this analysis provide evidence for mediation.

We do not conclude that there was no mediation, just that there was none visible to report. The spatial discrimination pulls apart the collaterals to one position in the chamber (such as in front of the 'short' key) or another, and this differentiation is easy to observe. Focussing on counting the collateral behaviors in the nonspatial discrimination, might have caused us to miss differences in topography that served as the mediators. Or, it is possible that the only mediation was accomplished by an autocorrelation matrix in the pigeons' heads; but that was not observed either.

\section{Discussion}

Table 1 shows that for every rat there were some collateral behaviors that showed a significant correlation with the temporal categorization response. We are all aware of the dangers of inferring causality from correlation, even though correlation is so often a good indicator that it constitutes the basis of most conditioning. Causal interpretations of correlations bear serious challenge only when there are better predictors available: Consider those alternate predictors provided by information processing theories, such as SET or the connectionist model. Since their accumulators and registers are not visible, the best alternative predictor they can offer is time itself. If we can better predict the temporal judgement from time than from collateral behaviors, then we have no reason to prefer the account given by the behavioral theory (nor would we yet have a reason to prefer SET's account). Table 1 gives the probability of responding 'short' or 'long' given that the time was $6 \mathrm{~s}$, and given that the time was $12 \mathrm{~s}$. These 
are simply the probabilities of being correct at those times, as judged by the experimenter. (The animals may in fact be conditioned to press the 'short' lever when they are grooming, and the 'long' lever when they are smelling it, and may therefore have different evaluations of their accuracy, considering this to be a grooming-report task). Notice that Rat 1's 'short' judgments are in fact much better predicted by whether or not it was grooming at the time it was queried, than by whether or not it was $6 \mathrm{~s}$ at the time it was queried, $98 \%$ of the time, if queried while grooming (whether at 6 or $12 \mathrm{~s}$ ) it would press the short lever, this is 22 points more likely than the $6 \mathrm{~s}$ base rate of $76 \%$. Its 'long' judgements are much better predicted by whether or not it was sniffing at the 'long' lever than by whether or not it was $12 \mathrm{~s}$ when queried. These are, de facto, 'groom' and 'smell me' levers. Rat 4's 'short' judgements were better predicted by sniffing at the lever than by time, and equally well predicted by whether it was mouthing the dispenser. It's 'long' judgements were better predicted by sniffing the lever than by time. Where two collateral behaviors are predictive, some may operate on some trials, others on other trials (as must be the case, since only one collateral behavior is recorded in each second). If the rats are engaged in certain collateral behaviors when the choice lights come on, knowing what those behaviors are gives you more information about the animal's subsequent choice than does the actual time. These 'temporal' judgements are behaviorally mediated. Analysis of the data from the remaining rats sustains this conclusion.

It is a less compelling story for the pigeons. For the spatially-differentiated responses, collateral behaviors were highly correlated with the subsequent temporal judgements. However, performance was so good on the easy discrimination that the collaterals offered only a few percentage points advantage over time per se, as seen in Table 2. Only for subject 91 in the difficult discrimination do we find that the collateral behaviors are a substantially better predictor of the temporal judgements than is time.

For the non-spatially differentiated discrimination, Table 3 shows that the number of key-pecks in a trial did not predict the errors that the subjects made. In a way this makes sense: If the animals could count up to thirty pecks relatively accurately, we should then wonder why they couldn't count 6-12 s with comparable accuracy. The topography of the collateral pecks may have varied over the course of the trials, had that been coded, it might have provided some evidence of mediation, but that was not done. So the behavioral hypothesis provides no added predictive ability in this case.

One reviewer was uncertain about the justification for calling high correlations between behaviors good evidence for mediation, noting that during a meal s/he lifts a fork before every bite, 'but this behavior has no role in mediating timing-it probably serves as a discriminative stimulus for taking a bite, but it does not appear to be related to interval timing'. This question raises an interesting issue. Some people actually use small or awkward utensils to pace consumption. An anthropologist from Mars might think the reviewer is timing while eating, perhaps to maintain a diet, and if the fork is removed and the eating stops, might mistakenly conclude that Killeen and Fetterman (1988) were correct. The proximity of the fork gives a cue as to when to open the mouth, and if the mouth is opened too late, we might blush and call it 'bad timing'. Much of the 'timing' we do is learning to exploit the natural rhythms of sequences of stimuli or responses in our environment, not sidereal time; comedians do not achieve good timing by consulting their Seikos. Thus, to assert that some chains of behavior are not related to timing prejudges the context in which they occur and the intentions of both the actors and the observers. We designed the present experiments as classic timing experiments, but do not aver that 'timing' is the best description of our subjects' behavior in them; just the conventional one.

If a collateral behavior is both necessary and sufficient for a 'long' or 'short' response, does this necessarily mean that timing is based on it? No, correlational evidence seldom affords that 
certainty. But in a number of cases such collateral behavior was a better predictor of the choice response than was time per se. Therefore, we are more justified in saying that the animals were discriminating their own behavior than that they were actually timing these intervals. If we insist in calling what successful subjects do in timing experiments 'timing', then our data suggest they accomplish this by attending to the rhythms of collateral behaviors. While imperfect, the observational evidence for behavioral mediation of timing is much stronger than that for cognitive mediation by accumulators and switches, because those have never been observed. The operationalization of time is further discussed in Killeen et al. (1997).

The current experiments called for temporal discrimination, not production. Although the behavior of the pigeons may seem impoverished, the contingencies of reinforcement operative in these experiments shape them to be in the right place to make the correct response when they are queried, and little else. Lejeune et al. (1998) recently reported observations of gerbils trained to step down from a platform after passage of a fixed time. In this production task, they found strings of collateral behavior whose rate and predictiveness of a step-down were consistent with BeT, as were the accuracy of timing and pattern of coefficients of variation. However, the collateral behaviors which best predicted step-down also occurred at other points in the intervals, and thus were not sufficient predictors. They concluded that their results lent no strong support to BeT. Their analysis reveals one of the difficulties of that theory: What had been introduced as a provisional hypothesis recommended by its simplicity and observational testworthyness - behavioral mediation of timing - is less clear cut than originally thought. In any case, the repetitive bouts of collateral behavior which Lejeune et al. (1998) witnessed will need their own timing account. This might be as simple as a fixed modal number of action patterns for each collateral response, perhaps something like 'lick paws until tongue gets dry', which would permit a recursive model [e.g. a compound Poisson process (Killeen and Weiss, 1987)], or it might be more complex.

In summary, the data from four rats provides excellent evidence for the behavioral part of the behavioral theory of timing; the data from two pigeons on the spatially-differentiated task add to that evidence. The non-spatially differentiated task provided no evidence for behavioral mediation.

\section{Acknowledgments}

This research was supported by NSF grants IBN 9408022 and NIMH K05 MH01293 to Peter Killeen (e-mail: killeen@asu.edu) and BNS 9021562 to J. Gregor Fetterman (e-mail: gfetter@IUPUI.edu).

\section{Appendix}

\section{Appendix A. The contingency table used to calculate Yule's $Q$ statistic ${ }^{*}$}

\begin{tabular}{|c|c|c|}
\hline & $R_{j}$ & $\overline{R_{j}}$ \\
\hline$C i$ & $a$ & $b$ \\
\hline$C_{i}$ & $c$ & $d$ \\
\hline
\end{tabular}




$$
z_{\mathrm{ij}}=\left(x_{i j}-m_{\mathrm{ij}}\right) / \sqrt{m_{\mathrm{ij}}\left(1-p_{+j}\right)\left(1-p_{i+}\right)}
$$

where $x_{i j}=$ observed joint frequency of $R$ and $C, m_{i j}=$ expected joint frequency of $R$ and $C, p_{+j}=$ unconditional probability of $R$, and $p_{i+}=$ unconditional probability of $C$ (these probabilities are the row and column marginals). The row $\overline{C_{i}}$ indicates the absence of behavior $C_{i}$ in that interval.

\section{References}

Bakeman, R.; Quera, V. Analyzing Interaction: Sequential Analysis with SDIS and GSEQ. Cambridge University Press; Cambridge: 1995. p. 155

Bakeman R, Quera V, McArthur D, Robinson BF. Detecting sequential patterns and determining their reliability with fallible observers. Psych Meth 1997;2:357-370.

Beam JJ, Killeen PR, Bizo LA, Fetterman JG. The role of reinforcement context in temporal production and categorization. Anim Learn Behav. 1998in press

Bem, DJ. Beliefs, Attitudes, and Human Affairs. Brooks/Cole; Belmont, CA: 1970.

Bizo L, White KG. The behavioral theory of timing: reinforcer rate determines pacemaker rate. J Exp Anal Behav 1994;61:19-33. [PubMed: 16812723]

Breukelaar JWC, Dalrymple-Alford JC. Timing ability and numerical competence in rats. J Exp Psychol: Anim Behav Process 1998;24:84-97. [PubMed: 9438968]

Carr, J.; Wilkie, D. Ordinal, phase, and interval timing. In: Bradshaw, C.; Szabadi, E., editors. Time and Behaviour: Psychological and Neurobiological Analyses. Elsevier Science B.V.; Amsterdam: 1997. p. 265-327.

Chatlosh DL, Wasserman EA. Delayed temporal discrimination in pigeons: a comparison of two procedures. J Exp Anal Behav 1987;47:299-309. [PubMed: 16812483]

Church, RM.; Broadbent, HA. A connectionist model of timing. In: Commons, ML.; Grossberg, S.; Staddon, JER., editors. Neural Network Models of Conditioning and Action. Erlbaum; Mahwah NJ: 1991. p. 225-240.

Church, RM.; Broadbent, HA.; Gibbon, J. Biological and psychological description of an internal clock. In: Gormezano, I.; Wasserman, EA., editors. Learning and Memory: The Behavioral and Biological Substrate. Lawrence Erlbaum Associates; Mahwah, NJ: 1992. p. 105-128.

Church RM, Broadbent HM. Alternative representations of time, number and rate. Cognition 1990;37:5581. [PubMed: 2269008]

Davis H, Peérusse R. Numerical competence in animals. Behav Brain Sci 1988;11:561-579.

Fetterman JG, Killeen PR. Adjusting the pacemaker. Learn Motiv 1991;22:226-252.

Fetterman JG, Killeen PR. Categorical scaling of time: implications for clock-counter models. J Exp Psychol: Anim Behav Process 1995;21:43-63. [PubMed: 7844506]

Feynman, RP.; Leighton, R. What Do YOU Care What Other People Think?: Further Adventures of a Curious Character. Norton; New York: 1988.

Gibbon J, Church RM. Comparison of variance and covariance patterns in parallel and serial models. J Exp Anal Behav 1992;57:393-406. [PubMed: 1602270]

Hall S, Oliver C. A graphical method to aid the sequential analysis of observational data. Behav Res Meth Instr Comp 1997;29:563-573.

Killeen PR, Bizo LA, Hall S. A clock not wound runs down. Behav Process. 1998submitted

Killeen PR, Fetterman JG. A behavioral theory of timing. Psychol Rev 1988;95:274-295. [PubMed: 3375401]

Killeen PR, Fetterman JG. Behavioral theory of timing: transition analyses. J Exp Anal Behav 1993;59:411-422. [PubMed: 8454961]

Killeen, PR.; Fetterman, JG.; Bizo, LA. Time's causes. In: Bradshaw, CM.; Szabadi, E., editors. Time and Behaviour: Psychological and Neurobiological Analyses. Elsevier Science B.V.; Amsterdam: 1997. p. $79-131$. 
Killeen PR, Weiss N. Optimal timing and the Weber function. Psychol Rev 1987;94:455-468. [PubMed: 3317471]

Lejeune H, Cornet S, Ferreira MA, Wearden JH. How do Mongolian gerbils (Meriones unguiculatus) pass the time? adjunctive behavior during temporal differentiation in gerbils. J Exp Psychol: Anim Behav Proc 1998;24:352-368.

Lejeune H, Wearden JH. The comparative psychology of fixed-interval responding: some quantitative analyses. Learn Motiv 1991;22:84-111.

Machado A. Learning the temporal dynamics of behavior. Psychol Rev 1997;104:241-265. [PubMed: 9127582]

McIntire K, Lundervold D, Calmes H, Jones C, Allard S. Temporal control in a complex environment: an analysis of schedule-related behavior. J Exp Anal Behav 1983;39:465-478. [PubMed: 16812331]

Meck, W. Application of a mode-control model of temporal integration to counting and timing behavior. In: Bradshaw, CM.; Szabadi, E., editors. Time and Behaviour, Psychological and Neurobiological Analyses. Elsevier Science B.V.; Amsterdam: 1997. p. 133-184.

Morgan L, Killeen PR, Fetterman JG. Changing rates of reinforcement perturbs the flow of time. Behav Process 1993;30:259-272.

Reid AK, Bacha G, Moran C. The temporal organization of behavior on periodic food schedules. J Exp Anal Behav 1993;59:1-27. [PubMed: 8433061]

Richelle, M.; Lejeune, H. Time in animal behavior. Pergamon Press; New York: 1980.

Shimp C, Moffitt M. Short-term memory in the pigeon: delayed-pair-comparison procedures and some results. J Exp Anal Behav 1977;28:13-25. [PubMed: 903742]

Staddon, JER. Schedule-induced behavior. In: Honig, WK.; Staddon, JER., editors. Handbook of Operant Behavior. Prentice-Hall; New York: 1977. p. 125-152.

Wearden JH. Do humans possess an internal clock with scalar timing properties? Learn Motiv 1991;22:59-83.

Wearden JH, Pentonvoak IS. Feeling the heat: body-temperature and the rate of subjective time, revisited. Q J Exp Psychol Sect B: Comp Physiol Psychol 1995;48:129-141.

Wilkening F, Levin I, Druyan S. Children's counting strategies for time quantification and integration. Devel Psychol 1987;23:823-831. 


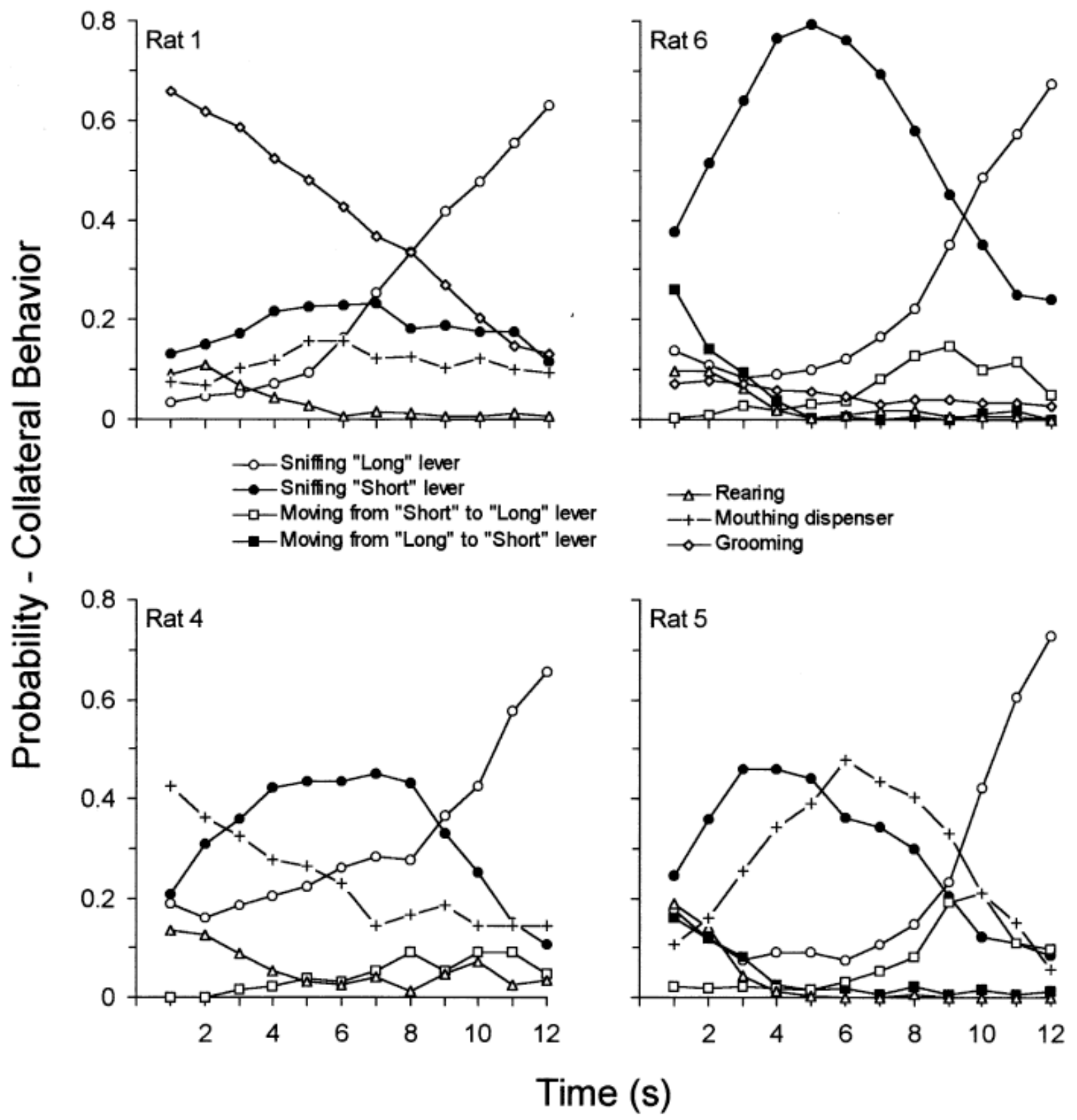

Fig. 1.

The probability of engaging in a collateral behavior as a function of time through the trial for four rats, trained to discriminate 6 from $12 \mathrm{~s}$. 


\section{Easy Discrimination}
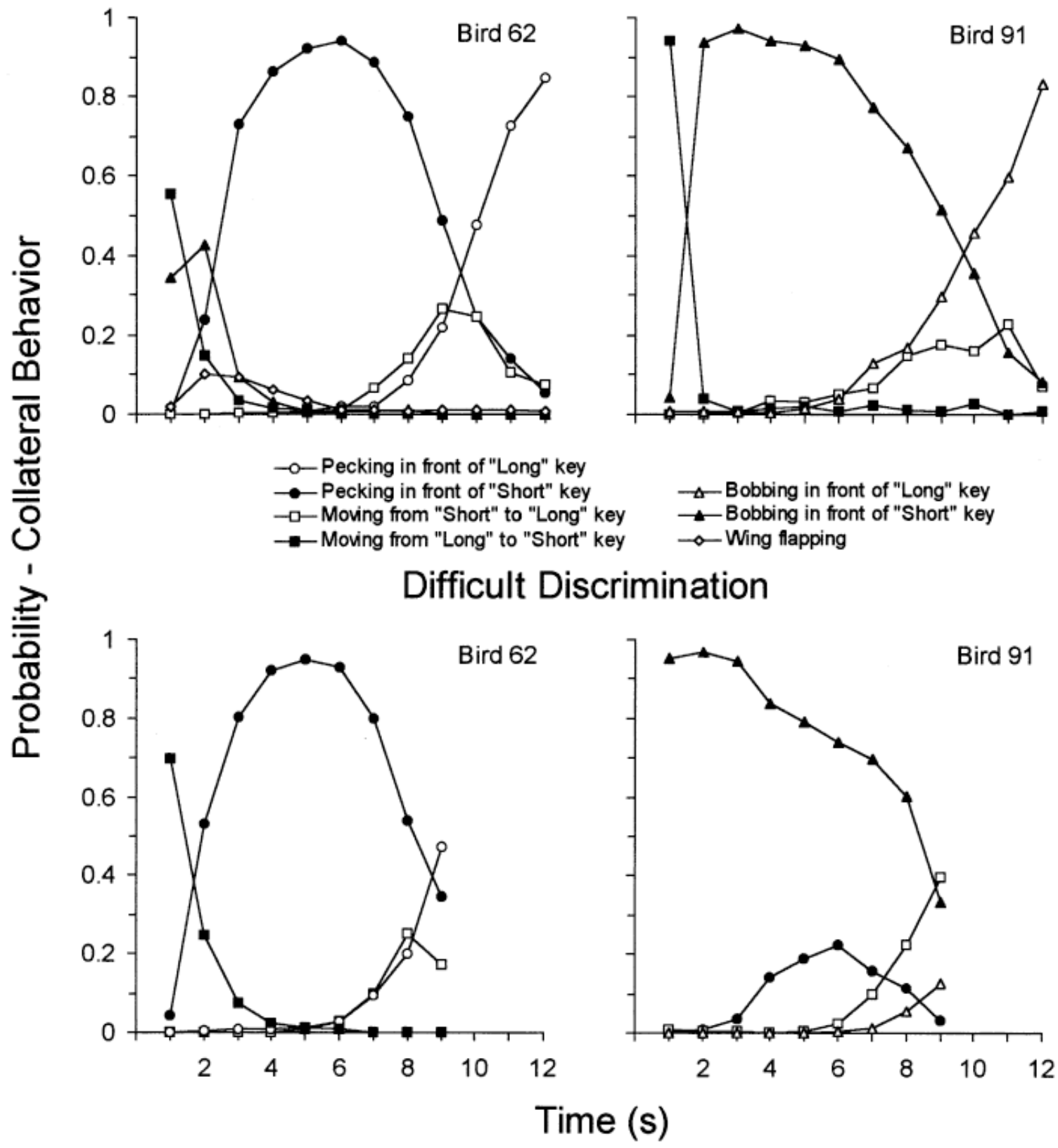

Fig. 2.

The probability of engaging in a collateral behavior as a function of time through the trial for two pigeons, trained to discriminate 6 from $12 \mathrm{~s}$ (top row) and 6 from $9 \mathrm{~s}$ (bottom row). The discriminating response was to the left or right response key. 


\section{Easy Discrimination}

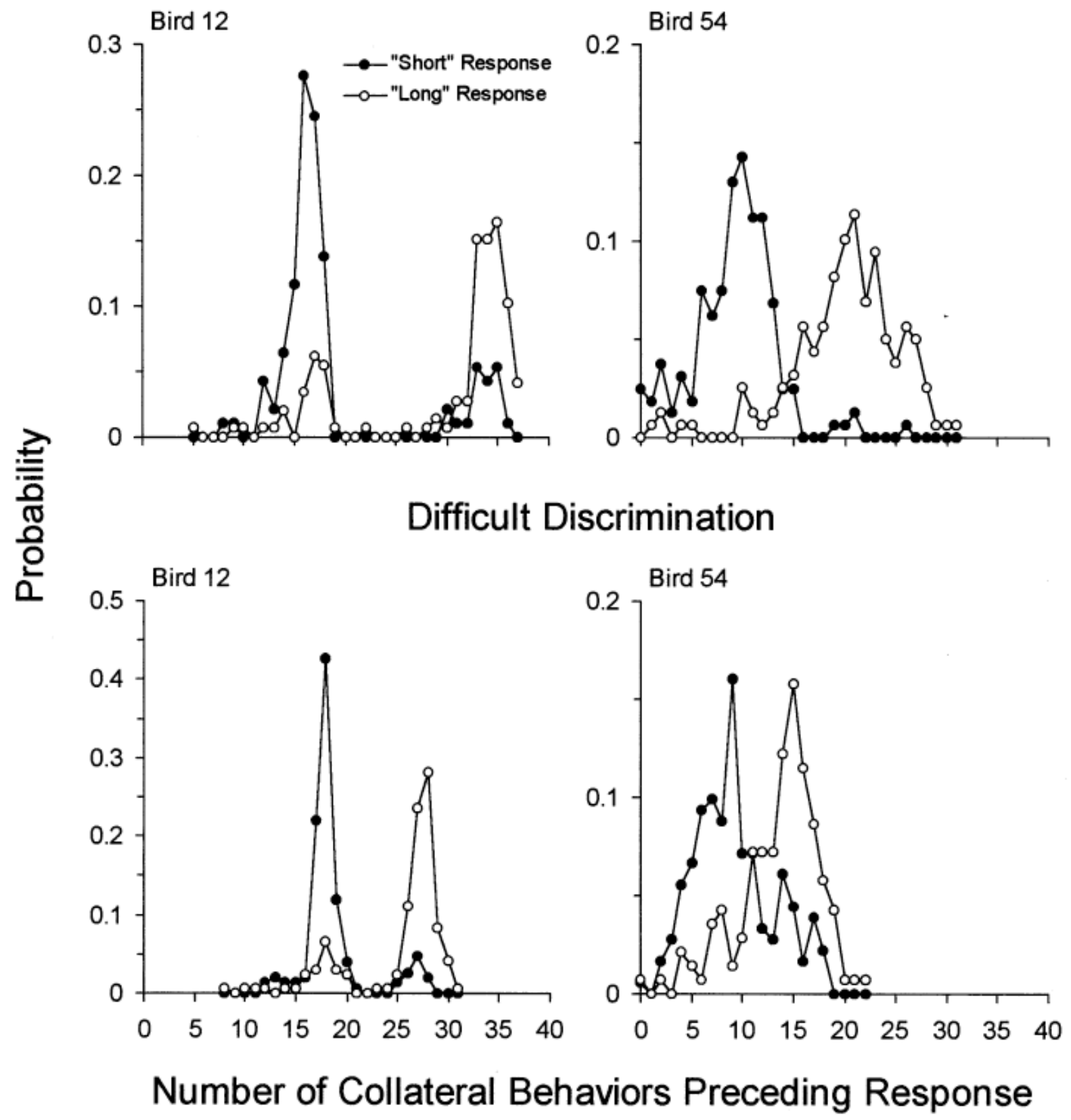

Fig. 3.

The distribution of collateral behaviors (head-bobbing in the corner for Bird 12, pecking the houselight for Bird 54) on trials in which the subject subsequently pecked the 'short' key (disks) or the 'long' key (circles). 


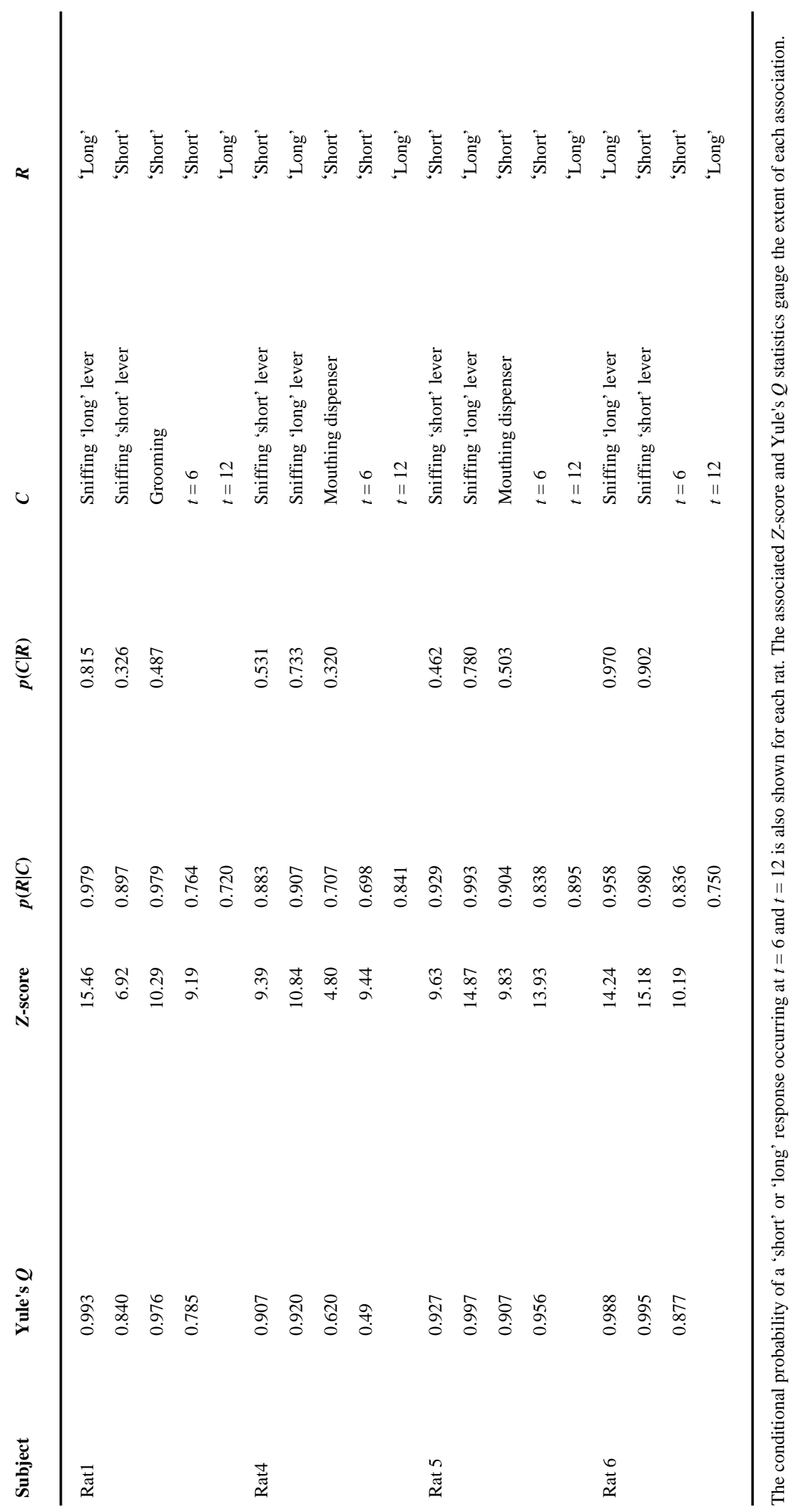


Fetterman et al.

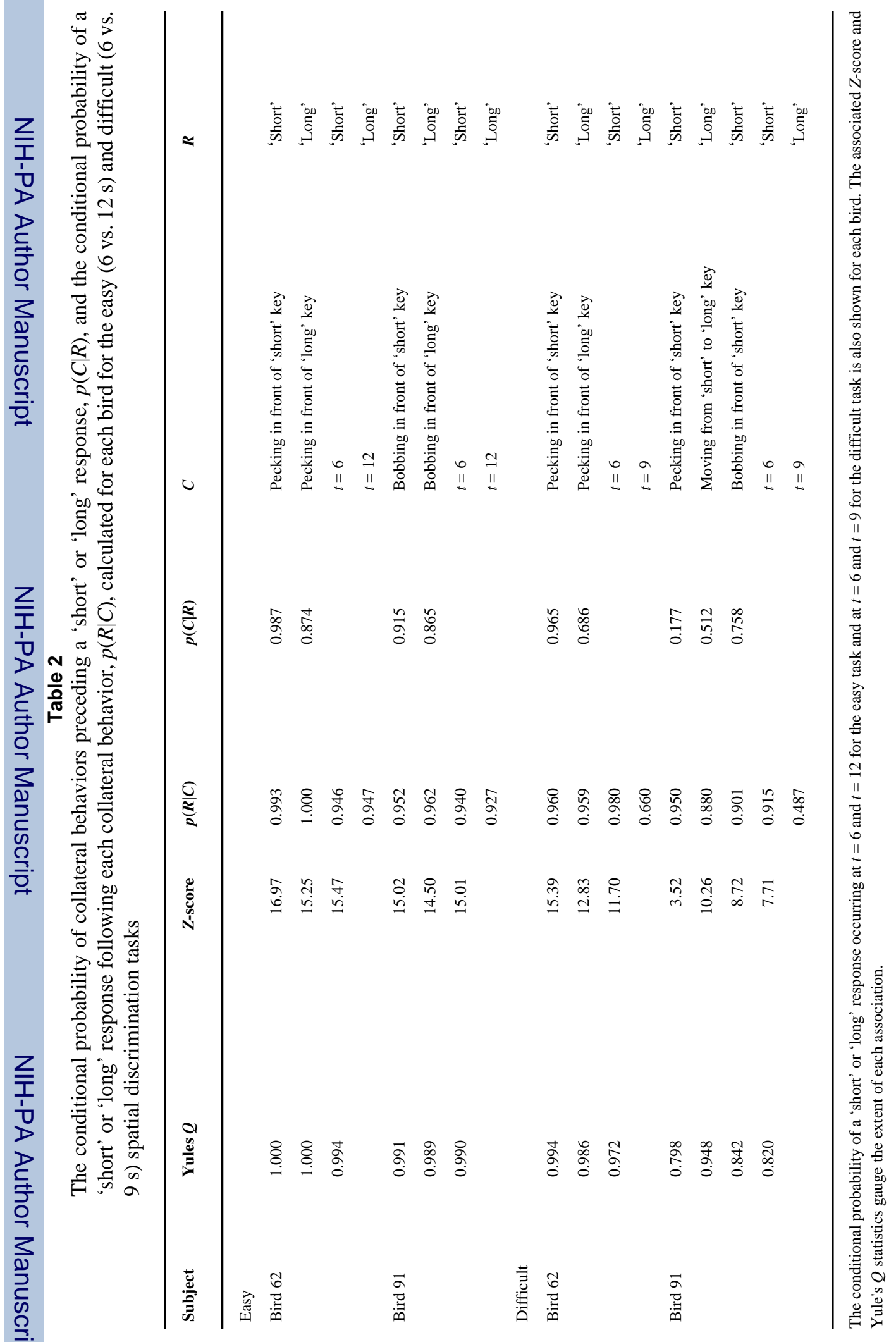


Table 3

Mean number of collateral behaviors emitted by each bird during the non-spatial discrimination task preceding either a 'short' or 'long' response on either short or long trials given an easy (6 vs. $12 \mathrm{~s}$ ) or difficult (6 vs. $9 \mathrm{~s}$ ) discrimination

\begin{tabular}{|c|c|c|c|c|}
\hline \multirow[t]{2}{*}{ Subject } & \multicolumn{2}{|l|}{ Short trials } & \multicolumn{2}{|l|}{ Long trials } \\
\hline & 'Short' & 'Long' & 'Short' & 'Long' \\
\hline \multicolumn{5}{|l|}{ Easy } \\
\hline Bird 12 & 15.87 & 16.57 & 33.42 & 30.42 \\
\hline Bird 54 & 8.88 & 5.75 & 21.4 & 20.86 \\
\hline \multicolumn{5}{|l|}{ Difficult } \\
\hline Bird 12 & 17.63 & 16.85 & 25.42 & 27.36 \\
\hline Bird 54 & 8.31 & 8.59 & 13.93 & 15.00 \\
\hline
\end{tabular}

